\title{
Shear Stress-Relative Slip Relationship at Concrete Interfaces
}

\author{
Keun-Hyeok Yang \\ Department of Plant \& Architectural Engineering, Kyonggi University, Suwon, Republic of Korea \\ Correspondence should be addressed to Keun-Hyeok Yang; yangkh@kgu.ac.kr \\ Received 1 May 2016; Revised 29 May 2016; Accepted 28 June 2016 \\ Academic Editor: Pavel Lejcek
}

Copyright (C) 2016 Keun-Hyeok Yang. This is an open access article distributed under the Creative Commons Attribution License, which permits unrestricted use, distribution, and reproduction in any medium, provided the original work is properly cited.

\begin{abstract}
This study develops a simple and rational shear stress-relative slip model of concrete interfaces with monolithic castings or smooth construction joints. In developing the model, the initial shear cracking stress and relative slip amount at peak stress were formulated from a nonlinear regression analysis using test data for push-off specimens. The shear friction strength was determined from the generalized equations on the basis of the upper-bound theorem of concrete plasticity. Then, a parametric fitting analysis was performed to derive equations for the key parameters determining the shapes of the ascending and descending branches of the shear stress-relative slip curve. The comparisons of predictions and measurements obtained from push-off tests confirmed that the proposed model provides superior accuracy in predicting the shear stress-relative slip relationship of interfacial shear planes. This was evidenced by the lower normalized root mean square error than those in Xu et al.s model and the CEB-FIB model, which have many limitations in terms of the roughness of the substrate surface along an interface and the magnitude of equivalent normal stress.
\end{abstract}

\section{Introduction}

The direct shear transfer mechanism has been examined significantly in highly stressed concrete interfaces such as those found in the details between columns and corbels, squat shear walls, and foundations, in dapped end beams, and in precast concrete assemblies [1]. Load transfer along concrete interfaces subjected to simultaneous shear and lateral forces applied normally to the interfaces is commonly explained using the shear friction mechanism [2,3]. Many empirical models [4-7] have been proposed to estimate the shear friction strength of the interfacial shear planes on the basis of different experimental programs, the shear friction theorem associated with the truss model, and/or the Mohr-Coulomb failure envelope. Yang [8] derived an integrated model for the shear friction strength of concrete interfaces based on the upper-bound theorem of concrete plasticity. The proposed models successfully demonstrated that the shear friction strength of concrete interfaces is significantly governed by concrete cohesion and equivalent normal stresses generated from the tensile resistance of transverse reinforcements crossing the interface and external forces applied normally to the interface. However, such models dealt insignificantly with shear displacement along the interface; as a result, very few equations are available to generalize the function of shear stress for shear slip assessment.

Knowledge of the shear stress-relative slip relationship at concrete interfaces is essential for ensuring serviceability and ductility of concrete structures. Xu et al. [9] attempted to assess the shear stress and slip characteristics of an initially uncracked concrete interface using a total of 36 sets of simulated data obtained from finite element analysis. In their nonlinear equations, the shear stress-relative slip relationship was characterized using a trigonometric function and reference values such as shear friction strength and different slip amounts. However, the roughness of the substrate surface along the interface was not considered in the shear stressrelative slip relationship proposed by Xu et al. Moreover, the reliability of the model needs to be further examined because the curve fitting is fundamentally followed by finite element analysis using the LS-DYNA software because of a lack of available test data. The CEB-FIP model code [3] determines the relative slip amount as a function of the dowel action of transverse reinforcements crossing the interfaces. The dowel action of transverse reinforcements for construction joints is explained simply as the product of the friction coefficient 


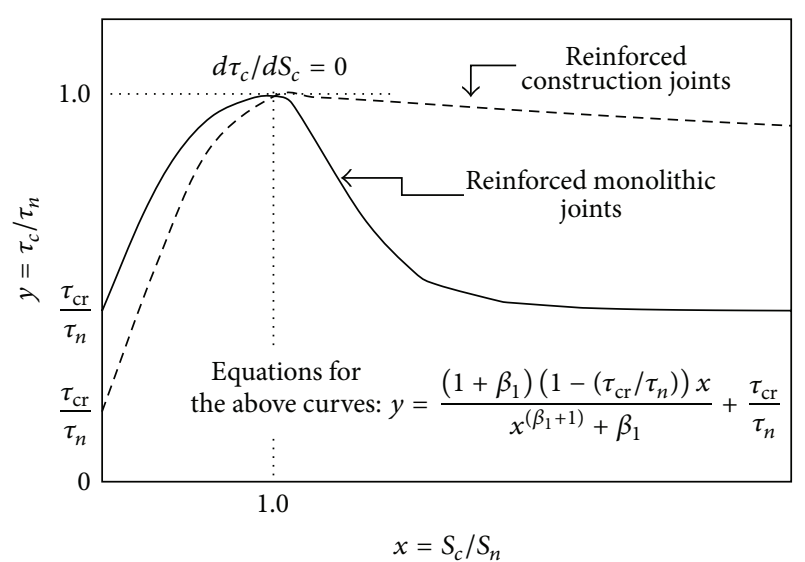

FIGURE 1: Generalization of shear stress-relative slip curve at concrete interfaces.

and the equivalent normal stress applied to the interface. However, the code does not specify the nonlinear behavior of the shear stress-relative slip curve, including the slope at the ascending and descending branches. Hence, a more sophisticated model needs to be developed in order to rationally understand the relative slip characteristics at concrete interfaces and ensure a design perspective of serviceability and strength in terms of shear friction resistance.

The present study proposes a relatively simple and rational model for the shear stress-relative slip curves of concrete interfaces with monolithic castings or smooth construction joints with no special treatment. For this model, a key parameter determining the slopes of the ascending and descending branches is formulated from a parametric fitting approach to the test data. The initial shear cracking stress, shear friction strength, and relative slip amount at the peak shear stress are selected as reference indices for the shear stress-relative slip curve. The initial shear cracking stress and relative slip amount corresponding to the shear friction strength are formulated from a nonlinear regression analysis using test data for push-off specimens. The shear friction strength is determined from the generalized equations on the basis of the upper-bound theorem of concrete plasticity [8]. The reliability of the developed model is verified using a normalized root mean square error obtained from a comparison of model estimates with the experimental data. The comparisons also examine the reliability of $\mathrm{Xu}$ et al's model for monolithic joints and the CEB-FIP model code for smooth construction joints.

\section{Mathematical Equation for Shear Stress- Relative Slip Curves}

According to Yang [8] and Xu et al. [9], the shear stressrelative slip relationship at concrete interfaces can be characterized as follows (see Figure 1): (1) with compatibility along the interface, slip displacement along the interfacial shear plane begins with the occurrence of a shear crack; (2) nonreinforced interfaces fail immediately with the occurrence of the initial shear crack, indicating that the shear stress-relative slip curve is insignificant for nonreinforced interfaces; (3) reinforced construction joints commonly exhibit a typical stress flow phenomenon, showing that the relative slip after the peak stress increases rapidly without a noticeable drop of the applied shear stress; (4) reinforced monolithic joints have greater slopes at the descending branch as compared to construction joints; and (5) after the peak stress, shear stresses applied to reinforced monolithic joints drop sharply up to a certain level and then remain constant, showing a stress flow phenomenon after the sharp stress drop. Hence, the shape of the shear stress-relative slip curve of concrete interfaces can be similarly generalized as a parabola with its vertex at the peak stress, as plotted in Figure 1. In this study, the following nonlinear equation is applied in generating a complete curve:

$$
y=\frac{\beta_{3} x}{x^{\beta_{2}}+\beta_{1}}+\beta_{4}
$$

where $y\left(=\tau_{c} / \tau_{n}\right)$ is the normalized shear stress, $x\left(=S_{c} / S_{0}\right)$ is the normalized relative slip, $\tau_{c}$ is the shear stress along the interfacial failure plane corresponding to relative slip $S_{c}, \tau_{n}$ is the shear friction strength, and $S_{0}$ is relative slip at peak shear stress. The physical meaning of the equation gives the following boundary conditions (see Figure 1): (1) $y=\tau_{\mathrm{cr}} / \tau_{n}$ for $x=0$, representing that the slip displacement along the interfacial shear plane begins with the occurrence of cracks, where $\tau_{\text {cr }}$ is the initial shear cracking stress; (2) $y=1$ for $x=1$, representing the peak stress; and (3) $d \tau_{c} / d S_{c}=0$ for $x=1$ at the peak point. From the first condition, $\beta_{4}$ as the $y$-intercept of the curve can be set to $\tau_{\text {cr }} / \tau_{n}$. Substituting the second condition into (1), $\beta_{3}$ can be written as $\left(1-\beta_{4}\right)(1+$ $\left.\beta_{1}\right)$. The tangential modulus at a point, $d \tau_{c} / d S_{c}$, is written as follows:

$$
\frac{d \tau_{c}}{d S_{c}}=\frac{\tau_{n}}{S_{0}} \frac{\left(1-\tau_{\mathrm{cr}} / \tau_{n}\right)\left(1+\beta_{1}\right)\left(x^{\beta_{2}}+\beta_{1}-\beta_{2} x^{\beta_{2}}\right)}{\left(x^{\beta_{2}}+\beta_{1}\right)^{2}} .
$$

The third condition for (2) is that $\beta_{2}$ is equal to $\beta_{1}+1$. Therefore, the shear stress-relative slip curve of concrete interfaces can be expressed in the following basic form with the key parameter $\beta_{1}$ :

$$
y=\frac{\left(1-\tau_{\mathrm{cr}} / \tau_{n}\right)\left(\beta_{1}+1\right) x}{x^{\beta_{1}+1}+\beta_{1}}+\frac{\tau_{\mathrm{cr}}}{\tau_{n}} .
$$

Note that the slopes of the ascending and descending branches of the curve depend on the value of $\beta_{1}$; however, the value of $\beta_{1}$ differs for each branch.

2.1. Initial Shear Cracking Stress $\left(\tau_{c r}\right)$. The applied shear stresses before the occurrence of a crack are mostly resisted by the cohesion and tensile strength of the concrete along the interfaces. Thus, $\tau_{\mathrm{cr}}$ of concrete interfaces is affected significantly by the concrete compressive strength $\left(f_{c}^{\prime}\right)$, roughness of the interfacial plane, and lateral stresses $\left(\sigma_{x}\right)$ normally applied to the interfaces whereas it is independent of transverse reinforcements crossing the interfaces [8]. To propose empirical equations for $\tau_{\mathrm{cr}}, 15$ datasets for monolithic joints and 39 datasets for smooth construction joints tested 


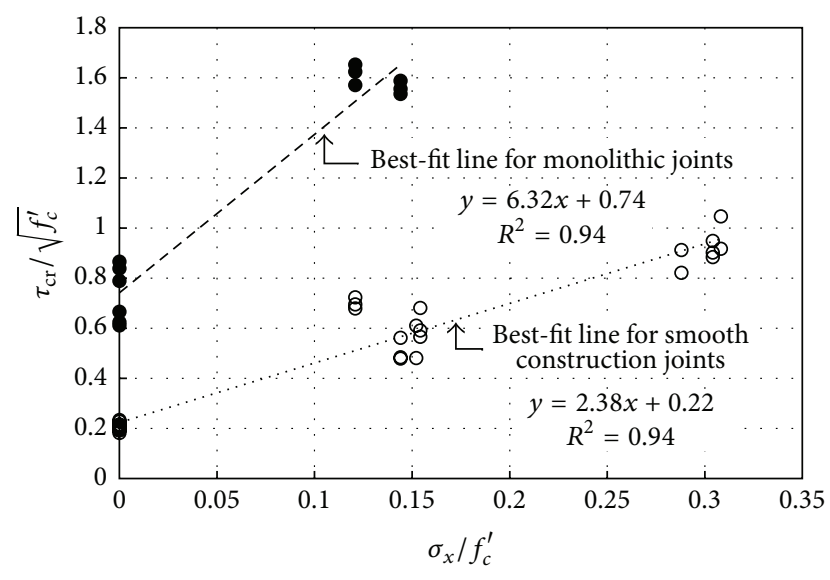

FIGURE 2: Regression analysis for $\tau_{\mathrm{cr}}$.

in the previous study were used for regression analysis. Note that this study classified a concrete interface placed with no intentional roughness depth or special treatment including sand blasting against previously hardened concrete as the smooth construction joint. In the datasets, $f_{c}^{\prime}$ and $\sigma_{x}$ varied between 29.8 and $62.5 \mathrm{MPa}$ and 0 and $18.8 \mathrm{MPa}$ $\left(0.3 f_{c}^{\prime}\right)$, respectively. It is commonly known [2] that $\tau_{\text {cr }}$ increases in proportion to the magnitude of $\sigma_{x}$ because the applied compressive stresses reduce the principle tensile stresses along the shear plane. Furthermore, construction joints commonly have lower $\tau_{\text {cr }}$ than monolithic joints due to reduced concrete cohesion along the interfacial plane [10]. Considering these experimental observations, each primary parameter was combined and adjusted repeatedly by the trial-and-error approach until a relatively higher correlation coefficient $\left(R^{2}\right)$ was obtained in establishing a basic model for $\tau_{\mathrm{cr}}$. From the empirical fitting approach with the test data, the following equations for $\tau_{\text {cr }}$ (in MPa) for concrete interfaces are proposed (Figure 2):

$$
\begin{aligned}
\tau_{\mathrm{cr}} & =A_{1} \frac{\sigma_{x}}{\sqrt{f_{c}^{\prime}}}+B_{1} \sqrt{f_{c}^{\prime}}, \\
A_{1} & =6.32 \mathrm{MPa}, \\
B_{1} & =0.74
\end{aligned}
$$

for monolithic joints,

$$
\begin{aligned}
A_{1} & =2.38 \mathrm{MPa}, \\
B_{1} & =0.22
\end{aligned}
$$

for smooth construction joints.

2.2. Shear Friction Strength $\left(\tau_{n}\right)$. Yang [8] derived an integrated model for shear friction strength $\left(\tau_{n}\right)$ of concrete interfaces on the basis of the upper-bound theorem of concrete plasticity. The failure mechanism of concrete interfaces was idealized and separated into two rigid blocks along the interfacial shear plane. Concrete was regarded as a rigid, perfectly plastic material obeying a modified Coulomb failure criterion. The model accounted for the effects of $\sigma_{x}$ and tensile stresses generated from transverse reinforcement on the shear friction action at interfacial shear cracks. In particular, from the sliding failure condition for a modified Coulomb material under pure shear stress, the model demonstrated that the friction angle $(\varphi)$ of concrete varies depending on the ratio of the effective tensile and compressive strengths of concrete, indicating that $\varphi$ increases with the increase of material brittleness. From comparison with 103 pushoff monolithic specimens, the proposed model was verified to have superior accuracy in predicting $\tau_{n}$ and consistent trends with experimental observations for the variation of $\tau_{n}$ according to different parameters. The model for a monolithic joint can be summarized as follows:

$$
\begin{aligned}
\tau_{n}= & \frac{V_{n}}{A_{c}} \\
= & \frac{1}{2} f_{c}^{*} \frac{1}{\cos \alpha}(l-m \sin \alpha)+\rho_{v f} f_{y} \frac{\left[\cos \left(\theta_{s}-\alpha\right)\right]}{\cos \alpha} \\
& +\sigma_{x} \tan \alpha, \\
f_{c}^{*}= & 0.79 \operatorname{Exp}\left[-0.03\left(\frac{f_{c}^{\prime}}{f_{\mathrm{co}}}\right)^{0.9}\left(\frac{\rho_{0}}{\rho_{c}}\right)^{1.6}\right] \cdot f_{c}^{\prime}, \\
\alpha= & \sin ^{-1}\left[\frac{1}{l}\left\{m-\frac{2\left(\rho_{v f} f_{y} \sin \theta_{s}+\sigma_{x}\right)}{f_{c}^{*}}\right\}\right], \\
\varphi= & 20.65\left(\frac{f_{t}^{*}}{f_{c}^{*}}\right)^{-0.21}, \\
\frac{f_{t}^{*}}{f_{c}^{*}}= & 0.064\left[\left(\frac{f_{c}^{\prime}}{f_{\mathrm{co}}}\right)\left(\frac{c_{0}}{d_{a}}\right)^{1.7}\left(\frac{\rho_{c}}{\rho_{0}}\right)^{0.1}\right]^{-0.43},
\end{aligned}
$$

where $l=1-2\left(f_{t}^{*} / f_{c}^{*}\right)(\sin \varphi /(1-\sin \varphi)), m=1-$ $2\left(f_{t}^{*} / f_{c}^{*}\right)(1 /(1-\sin \varphi)), \alpha$ is the angle between the relative displacement $(\delta)$ at the midpoint of the yield line and the failure plane, $f_{c}^{*}$ is the effective compressive strength of concrete, $f_{t}^{*}$ is the effective tensile strength of concrete, $\rho_{v f}$ and $f_{y}$ are the ratio and yield strength, respectively, of transverse reinforcements crossing the interface, $\theta_{s}$ is the inclination of transverse reinforcements relative to the interface, $f_{\text {co }}(=10 \mathrm{MPa})$ is the reference value for concrete compressive strength, $\rho_{0}\left(=2300 \mathrm{~kg} / \mathrm{m}^{3}\right)$ is the reference value for the concrete unit weight $\left(\rho_{c}\right)$, and $c_{0}(=25 \mathrm{~mm})$ is the reference value for the maximum aggregate size $\left(d_{a}\right)$.

The failure mechanism in construction joints is similar to that in monolithic joints, showing a separation into two rigid blocks at failure. The failure plane of monolithic joints is commonly interlocked with aggregate particles, which results in improvement of friction resistance against sliding shear displacement. Meanwhile, the construction joints commonly fail along the surface of the concrete placed separately against the previously hardened concrete. Thus, the substrate surfaces along a construction joint are completely undamaged, meaning that the aggregate particles play no role in sliding 
resistance. This implies that the failure surface of construction joints has a constant sliding direction. Hence, from the relationship between friction angle and the ratios of the maximum and minimum principal strains in the sliding plane along construction joints, the angle $\alpha$ in (6) can be assumed to be equal to the frictional angle $\left(\varphi^{\prime}\right)$ of concrete [11]. As the shear friction of concrete along construction joints is regarded to be entirely resisted by concrete cohesion, the tensile strength of concrete is neglected. Furthermore, $f_{c}^{*}$ for construction joints under sliding failure is expressed as $2 c^{\prime}\left(\cos \varphi^{\prime}\right) /\left(1-\sin \varphi^{\prime}\right)$, where $c^{\prime}$ is the concrete cohesion along construction joints. Overall, (6) for construction joints can be written as follows:

$$
\tau_{n}=c^{\prime}+\rho_{v f} f_{y} \frac{\cos \left(\theta_{s}-\varphi^{\prime}\right)}{\cos \varphi^{\prime}}+\sigma_{x} \tan \varphi^{\prime}
$$

For over-reinforced interfaces, the concrete splitting failure is governed prior to the yield of the transverse reinforcement [5]. Hence, the upper limit for $\rho_{v f} f_{y}$ needs to be considered in (6) and (11) through further collection of experimental data. For construction joints with transverse reinforcements arranged perpendicular to the interface, (11) can be written as $\tau_{n}=c^{\prime}+\left(\rho_{v f} f_{y}+\sigma_{x}\right) \tan \varphi^{\prime}$, which is general form for the relationship between shear friction strength and equivalent normal stresses $\left(\sigma_{\mathrm{eq}}=\rho_{v f} f_{y}+\sigma_{x}\right)$. Hwang and Yang [12] determined the values of $c^{\prime}$ and $\varphi^{\prime}$ in (11) using test results measured for push-off specimens with smooth construction joints. From the regression analysis of test data, they proposed the optimal values of $c^{\prime}$ and $\varphi^{\prime}$ for smooth construction joints as follows:

$$
\begin{aligned}
c^{\prime} & =0.11\left(f_{c}^{\prime}\right)^{0.65}, \\
\varphi^{\prime} & =32.8^{\circ} .
\end{aligned}
$$

2.3. Relative Slip $\left(S_{0}\right)$ at Peak Shear Stress. According to the CEB-FIP model code 90 [3], the amount of relative slip $\left(S_{0}\right)$ at the peak shear stress depends significantly on the magnitude of $\sigma_{\text {eq }}$ because the elongation of reinforcing bars crossing the interfacial shear plane and externally applied lateral forces act as clamping stresses along the interfacial failure plane. Meanwhile, $S_{0}$ is affected insignificantly by $f_{c}^{\prime}$ because cohesion and tensile resistance of concrete at the crack plane do not contribute to the restriction of slip displacement [13]. Overall, it can be considered that the amount of relative slip depends on the applied confining stresses rather than the material properties. Very little information on test data for $S_{0}$ is provided in the available literature. Using 52 pieces of test data compiled from push-off specimens tested by Yang [8] and numerically analyzed by Xu et al. [9], the relationship between $S_{0}$ (in $\mathrm{mm}$ ) and $\sigma_{\text {eq }}$ (in $\mathrm{MPa}$ ) was examined, as plotted in Figure 3. Thus, the following equations for $S_{0}$ were obtained:

$$
\frac{S_{0}}{S_{1}}=A_{2}\left(\frac{\sigma_{\mathrm{eq}}}{\sqrt{f_{c}^{\prime}}}\right)^{B_{2}}+C_{2},
$$

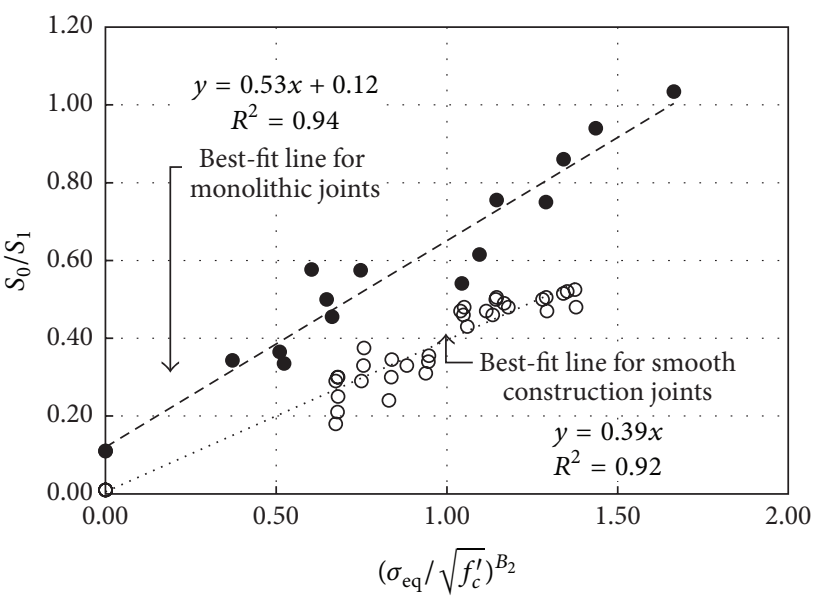

FIgURE 3: Regression analysis for $S_{0}$.

$$
\begin{aligned}
A_{2} & =0.53, \\
B_{2} & =0.70, \\
C_{2} & =0.12 \\
A_{2} & =0.39, \\
B_{2} & =0.30, \\
C_{2} & =0
\end{aligned}
$$$$
\text { for monolithic joints, }
$$

for smooth construction joints,

where $S_{1}(=1 \mathrm{~mm})$ is the reference amount for relative slip.

2.4. Key Parameter $\beta_{1}$. It is not an easy task to identify reference points in the shear stress-relative slip curve to solve the value of $\beta_{1}$ in (3) because the amount of relative slip is affected insignificantly by concrete properties such as compressive strength, cohesion, and friction angle. Hence, the present study employed an empirical fitting method using experimentally measured curves [8] to formulate the key parameter $\beta_{1}$, which determines the slopes of the ascending and descending branches of the curve. The values for $\tau_{\mathrm{cr}}, \tau_{n}$, and $S_{0}$ derived in the preceding subsections were substituted into (3) for a given push-off specimen. Then, the values of $\beta_{1}$ for the ascending and descending branches were adjusted until a relatively lower normalized root mean square error value was obtained in comparison with predicted and experimental curves for each push-off specimen. Based on the empirically obtained results for $\beta_{1}$, statistical optimization was conducted to formulate the following best-fit equations for the slopes of the ascending (Figure 4(a)) and descending (Figure 4(b)) branches.

(i) Ascending branch $\left(S_{c} \leq S_{0}\right)$ :

$$
\beta_{1}=0.024\left(\frac{\sigma_{\mathrm{eq}}}{\sigma_{0}}\right)+0.73
$$




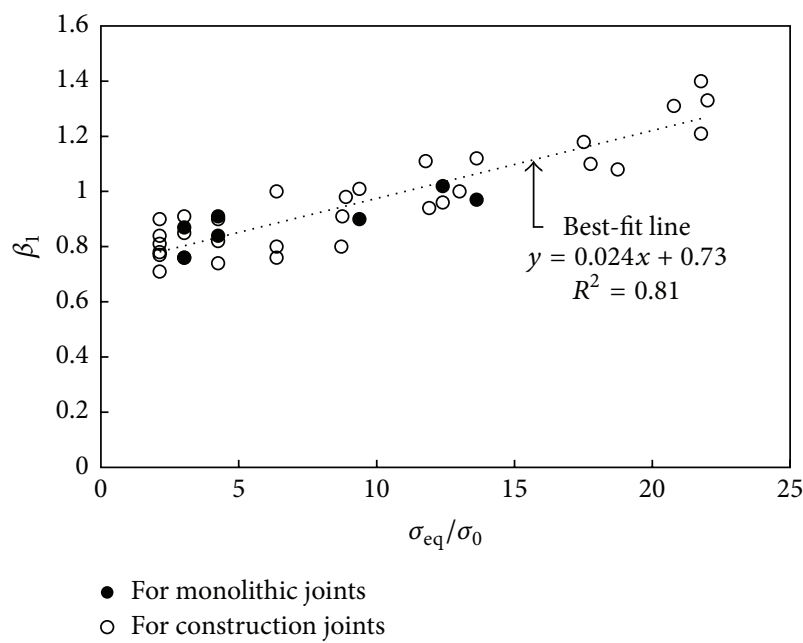

(a)

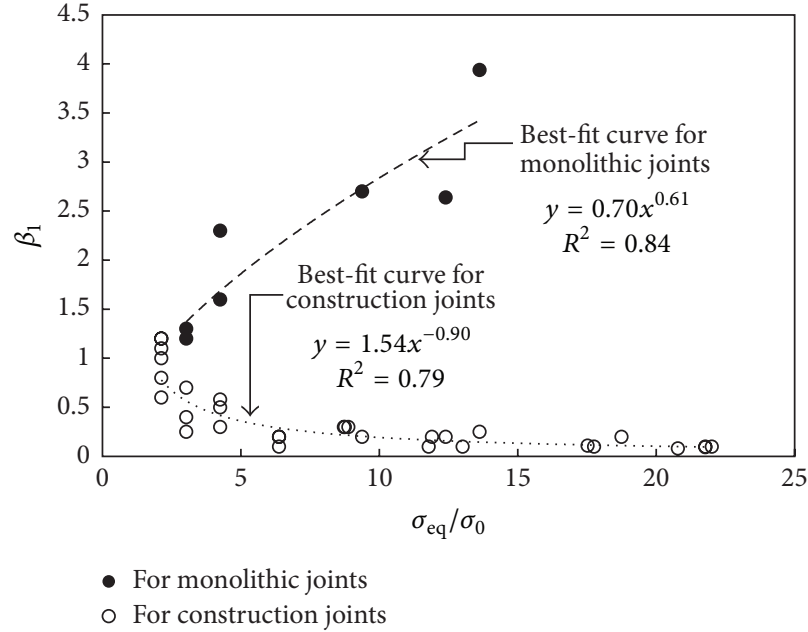

(b)

FIGURE 4: Regression analysis for $\beta_{1}$ determined from the empirical fitting approach using (3) and push-off test data: (a) ascending branch; (b) descending branch.

(ii) Descending branch $\left(S_{c}>S_{0}\right)$ :

$$
\begin{aligned}
& \beta_{1}=0.7\left(\frac{\sigma_{\mathrm{eq}}}{\sigma_{0}}\right)^{0.61} \text { for monolithic joints, } \\
& \beta_{1}=1.54\left(\frac{\sigma_{\mathrm{eq}}}{\sigma_{0}}\right)^{-0.90}
\end{aligned}
$$

for smooth construction joints,

where $\sigma_{0}(=1 \mathrm{MPa})$ is the reference value for equivalent normal stresses.

The above equations and Figure 4 physically reveal that the slope of the ascending branch is minimally affected by the roughness of the substrate surface along the interface, whereas the descending branch against $\sigma_{\text {eq }}$ is more sensitive for monolithic joints than for construction joints. As $\sigma_{\text {eq }}$ increases, the slope of the descending branch for monolithic joints becomes steeper, indicating a greater drop in shear stress after the peak stress, whereas that for construction joints is alleviated significantly, indicating that no stress drop is observed after the peak stress when $\sigma_{\text {eq }}$ is greater than approximately 10 .

In summary, a shear stress-relative slip model for concrete interfaces is presented in Table 1. The table also includes the CEB-FIP model code for smooth construction joints and Xu et al.s model derived from regression analysis using analytical data for monolithic joints without initial cracks. It is noted that the size effect on the developed model is not considered in the present model because all datasets were compiled for push-off specimens with relatively small shear sections of less than $31500 \mathrm{~mm}^{2}$. In addition, the proposed model needs to be modified for rough construction joints because of the variation of the concrete cohesion and frictional angle. Dahl [14] found that the roughness obtained by mechanical treatment led to an approximately 50\% increase of the concrete cohesion $c^{\prime}$. However, the value of $c^{\prime}$ for roughened construction joints depends on the depth of roughness and concrete compressive strength. Hence, further elaborated tests need to be conducted to determine the value of $c^{\prime}$ for rough construction joints. The shear transfer contribution of concrete cohesion also needs to be neglected for interfaces under repeated cyclic loading.

\section{Comparison with Test Results}

A total of 44 datasets for shear stress-relative slip curves measured from push-off specimens were used for comparison with prediction models. The test parameters in these specimens ranged as follows: $f_{c}^{\prime}$ was between 29.8 and $62.5 \mathrm{MPa}$ for monolithic and construction joints; $\sigma_{x}$ was between 0 and $9.38 \mathrm{MPa}\left(0.15 f_{c}^{\prime}\right)$ for monolithic joints and 0 and $18.75 \mathrm{MPa}\left(0.30 f_{c}^{\prime}\right)$ for construction joints; $\rho_{v f} f_{y}$ was between 0 and $4.25 \mathrm{MPa}$ for monolithic joints and 0 and 6.37 MPa for construction joints; and $\sigma_{\text {eq }}$ was between 0 and $13.62 \mathrm{MPa}\left(0.22 f_{c}^{\prime}\right)$ for monolithic joints and 0 and $22.01 \mathrm{MPa}$ $\left(0.37 f_{c}^{\prime}\right)$ for construction joints. A direct comparison was made between experimental data and estimates obtained from the developed model. The comparison also includes estimates determined from the CEB-FIP model code for 33 push-off specimens with smooth construction joints and from Xu et al's model for 11 specimens with monolithic joints. Figure 5 shows randomly selected comparisons of the predicted and measured curves for push-off specimens with various joints and $\sigma_{\mathrm{eq}}$ values. Table 2 gives the normalized root mean square error $\left(\gamma_{e}\right)$ calculated for each shear stressrelative slip curve. The mean $\left(\gamma_{e, m}\right)$ and standard deviation $\left(\gamma_{e, s}\right)$ of $\gamma_{e}$ values for the groups divided according to the joint type were compared along with direct comparison of the shear stress-relative slip curves shown in Figure 5.

$\mathrm{Xu}$ et al. empirically fitted the shear stress-relative slip curves simulated from finite element analysis with regard to monolithic push-off specimens without initial cracks. In 
TABLE 1: Summary of proposed models for shear stress-relative slip relationship.

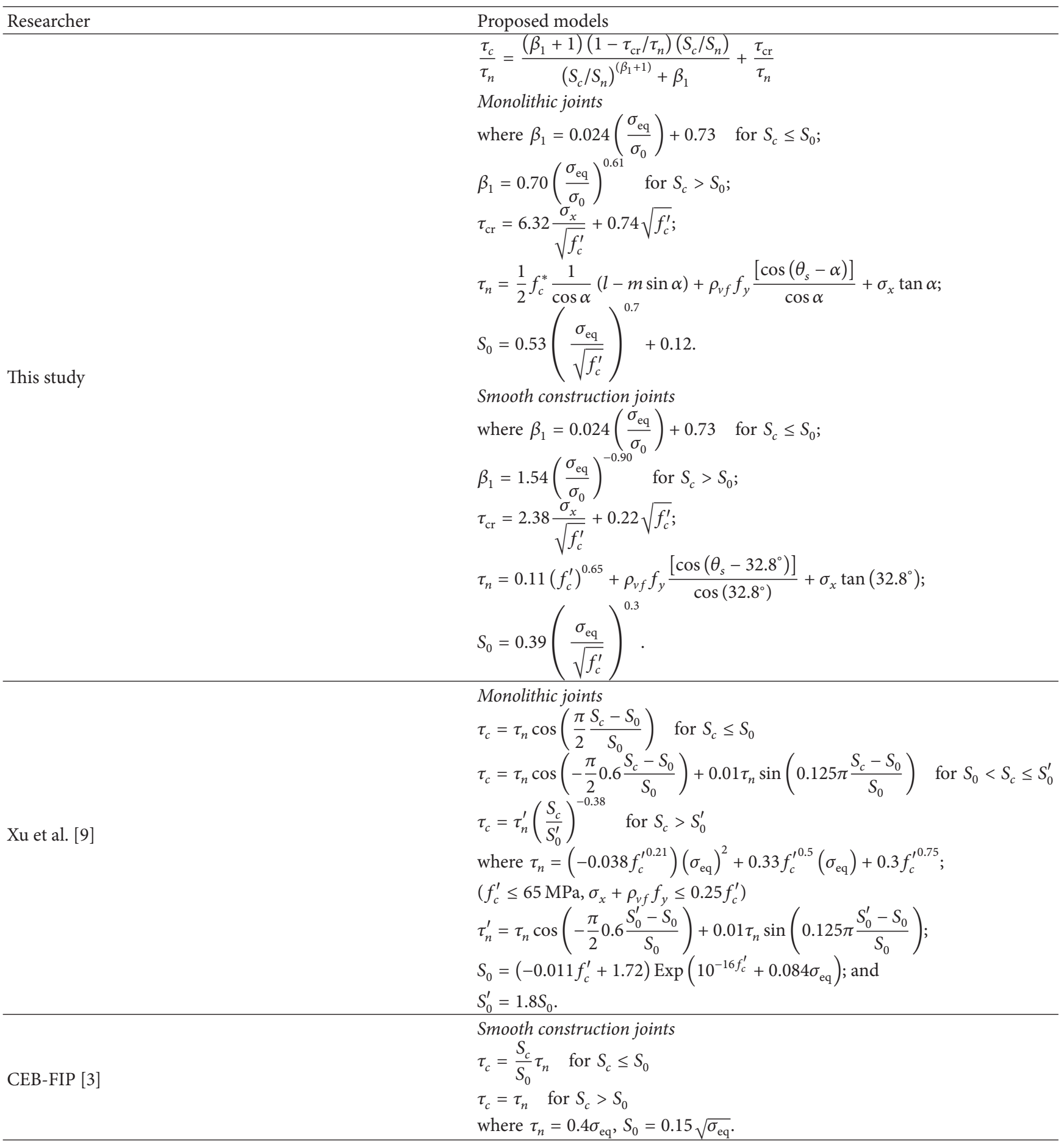

the fitting equations, the ascending branch was formulated using a cosine function connecting the origin and the peak point, whereas the descending branch was expressed by a combination of cosine and sine functions to reproduce an inflection point at $1.8 S_{0}$. The shear friction strength was formulated as a function of $f_{c}^{\prime}$ and $\sigma_{\text {eq }}$ under the limiting conditions of $f_{c}^{\prime} \leq 65 \mathrm{MPa}$ and $\sigma_{\text {eq }} \leq 0.25 f_{c}^{\prime}$. The equations assumed that the slip begins with loading, indicating that the relative slip is not affected by the occurrence of the initial crack along the interfacial shear plane. The accuracy of the equations for monolithic joints is clearly poor, as shown in Figure 5(a). The predicted amount of relative slip is generally greater than the experimental value. Moreover, the equations tend to overestimate $\tau_{n}$ for interfaces subjected to externally applied normal stresses in compression. As a result, Xu et al.'s equations produce a relatively high value of $\gamma_{e, m}$ (more than 


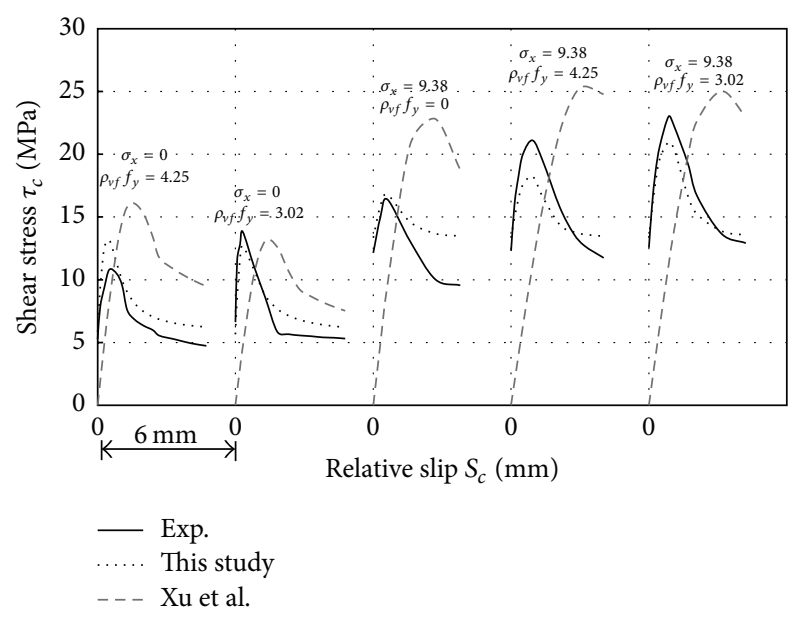

(a)

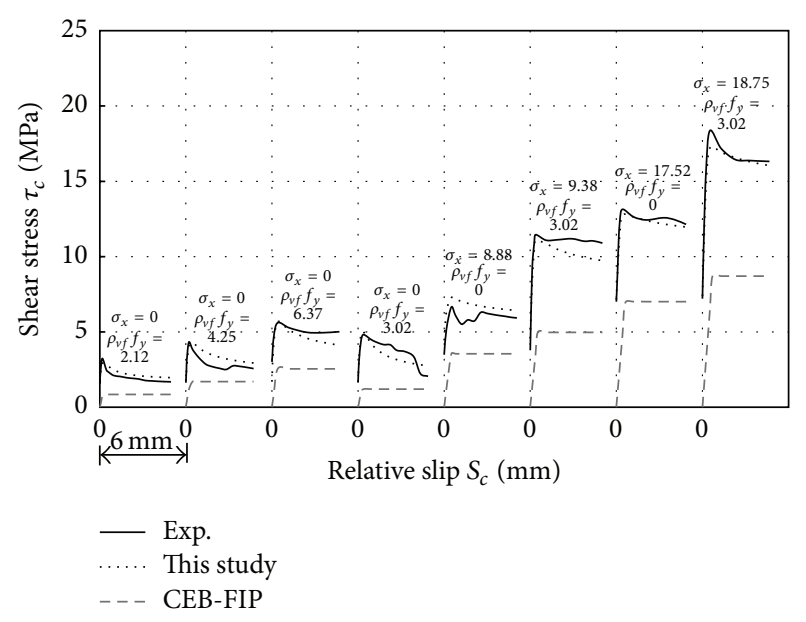

(b)

FIGURE 5: Typical comparisons of predicted shear stress-relative slip curves with experimental results: (a) push-off specimens with monolithic joints; (b) push-off specimens with smooth construction joints.

TABLE 2: Comparisons of normalized root mean square error obtained from each shear stress-relative slip curve.

\begin{tabular}{lcccc}
\hline $\begin{array}{l}\text { Statistical } \\
\text { value }\end{array}$ & \multicolumn{2}{c}{$\begin{array}{c}\text { Monolithic joints } \\
\text { Xu et al. }\end{array}$} & $\begin{array}{c}\text { Smooth construction } \\
\text { joints }\end{array}$ \\
& This study & This & CEB-FIP \\
\hline$\gamma_{e, m}$ & 0.41 & 1.85 & 0.52 & 1.98 \\
$\gamma_{e, s}$ & 0.16 & 0.49 & 0.36 & 0.32 \\
\hline
\end{tabular}

Note: normalized root mean square error, $\left(\gamma_{e}\right)=\left(1 /\left(\tau_{c}\right)_{m}\right) \sum\left[\left(\left(\tau_{c}\right)_{\operatorname{Exp}}-\right.\right.$ $\left.\left.\left(\tau_{c}\right)_{\text {Pre }}\right)^{2} / n\right]^{1 / 2}$, where $\left(\tau_{c}\right)_{m}$ is the mean stress in the measured shear stressrelative slip curve, $\left(\tau_{c}\right)_{\operatorname{Exp}}$ and $\left(\tau_{c}\right)_{\text {Pre }}$ are the experimental and predicted shear stresses, respectively, and $n$ is the number of points in the experimental curve.

(i) $\gamma_{e, m}$ and $\gamma_{e, s}$ are the mean and standard deviation, respectively, of the $\gamma_{e}$ values calculated for each curve.

1.8) for monolithic joints, as shown in Table 2. Furthermore, the value of $\gamma_{e}$ tends to increase slightly with the increase of $\sigma_{\text {eq }}$, as plotted in Figure 6(a).

CEB-FIP model code considers that the slip along the interfacial shear plane is entirely resisted by the dowel action generated from transverse reinforcements crossing the interface. The code recommends the use of 0.4 as a friction coefficient for smooth construction joints. Thus, the shear friction strength is expressed as $0.4 \sigma_{\text {eq }}$ and the corresponding slip amount (in $\mathrm{mm}$ ) is estimated as $0.15 \sqrt{\sigma_{\text {eq }}}$. The shear stress-relative slip response for smooth construction joints is modeled as bilinear behavior with a fully plastic flow response without a stress drop beyond $S_{0}$. Similar to Xu et al.s equations, the code overestimates the amount of relative slip at the ascending branch. The code considerably underestimates the shear friction strength but tends to overestimate the slope of the descending branch, as shown in Figure 5(b). As a result, the code gives a high value of $\gamma_{e, m}(=1.98)$ for smooth construction joints. In particular, greater $\gamma_{e}$ values are observed when $\sigma_{\text {eq }}$ is less than 5.0 (Figure 6(b)).
On the contrary, the predictions from the model proposed in this study are in better agreement with test results, indicating $\gamma_{e, m}$ and $\gamma_{e, s}$ values of 0.42 and 0.16 , respectively, for monolithic joints, and 0.52 and 0.36 , respectively, for smooth construction joints. The calculated shear stress-relative slip curves correspond well with the measured curves, particularly in terms of the following: (1) the slip along the interfacial shear plane initiates with the occurrence of cracking; (2) the shear friction strength and the corresponding slip amount increase with increasing $\sigma_{\text {eq }}$; (3) a more rapid stress drop at the descending branch is observed for monolithic joints than for smooth construction joints; and (4) the predicted values of $\tau_{\mathrm{cr}}, \tau_{n}$, and $S_{0}$ are in good agreement with test results. Overall, the proposed model provides superior accuracy in predicting shear stress-relative slip relationship of interfacial shear planes with monolithic castings or smooth construction joints. The value of $\gamma_{e}$ determined from the proposed model is less sensitive to the variation of $\sigma_{\mathrm{eq}}$ (Figure 6) as compared with that calculated from Xu et al.'s model and the CEB-FIP model code. It is also noted that the proposed model can be applied relatively simply with the parameter $\beta_{1}$, which is a function of $\sigma_{\text {eq }}$.

\section{Conclusions}

Based on the research summarized in this paper, the following conclusions may be drawn:

(1) The previous shear stress-relative slip models have many limitations in terms of the roughness of the substrate surface along the interface and the magnitude of the equivalent normal stress $\left(\sigma_{\text {eq }}\right)$. Xu et al.s model highly overestimates the shear friction strength $\left(\tau_{n}\right)$ and the propagation of relative slip along monolithic joints without initial cracks. The CEBFIP model considerably underestimates $\tau_{n}$ for smooth construction joints but overestimates the slope of the descending branch. 


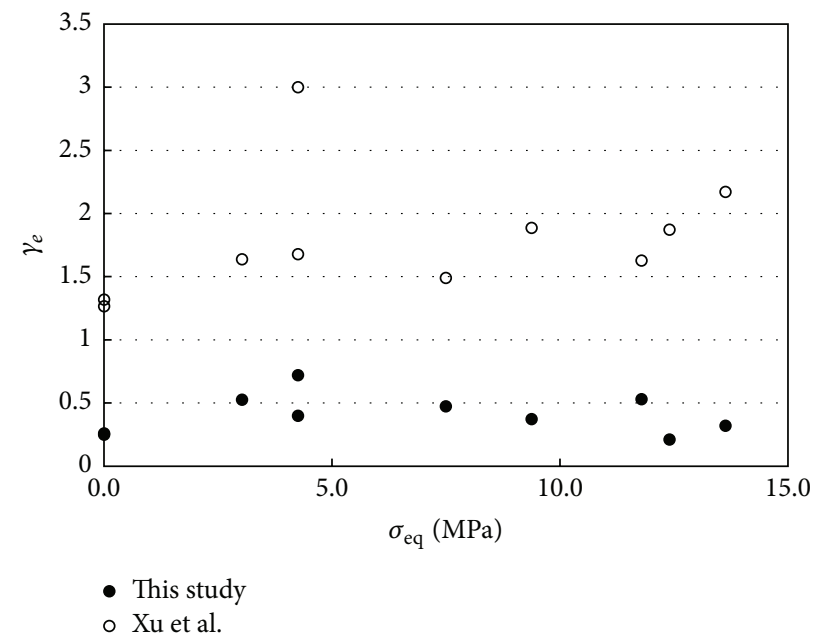

(a)

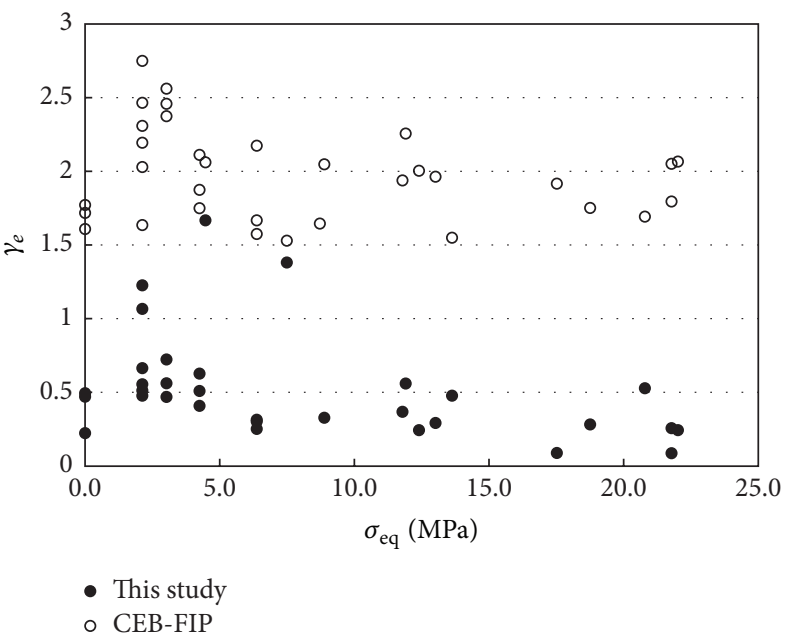

(b)

FIGURE 6: Comparisons of normalized root mean square error $\left(\gamma_{e}\right)$ against $\sigma_{\mathrm{eq}}$ : (a) monolithic joints; (b) smooth construction joints.

(2) The initial shear cracking stress increases in proportion to the increase in the concrete compressive strength $\left(f_{c}^{\prime}\right)$ and lateral stresses $\left(\sigma_{x}\right)$ applied normally to the interfaces. The relative slip $\left(S_{0}\right)$ at the peak stress also increases as $\sigma_{\text {eq }}$ increases.

(3) The key parameter $\beta_{1}$ defines the shape of the shear stress-relative slip curve. $\beta_{1}$ values are established to explain the effect of roughness of the substrate surface along the interface on the different slopes of the ascending and descending branches.

(4) The proposed model provides superior accuracy in predicting the shear stress-relative slip relationship of interfacial shear planes with monolithic castings or smooth construction joints. This was evidenced by the low normalized root mean square error compared with that of the other models.

\section{Notations}

$A_{v f}$ : Area of transverse reinforcement crossing the interfacial failure plane

$c_{0}$ : Reference aggregate size $(=25 \mathrm{~mm})$

$c^{\prime}$ : Cohesion of concrete along construction joints

$d_{a}$ : Maximum size of aggregate

$f_{c}^{\prime}$ : Compressive strength of concrete

$f_{\text {co }}$ : Reference compressive strength of concrete $(=10 \mathrm{MPa})$

$f_{c}^{*}$ : Effective compressive strength of concrete

$f_{t}$ : Tensile strength of concrete

$f_{t}^{*}$ : Effective tensile strength of concrete

$f_{y}$ : Yield strength of transverse reinforcement

$R^{2}$ : Correlation coefficient between predictions and experiments

$S_{0}: \quad$ Relative slip amount at $\tau_{n}$

$S_{c}$ : Relative slip amount

$V_{n}$ : Shear friction strength at the interfacial failure plane $\alpha$ : Angle between the relative displacement at the chord midpoint and failure plane

$\gamma_{e}$ : Normalized root mean square error ratio between experimental curve and predictions

$\gamma_{e, m}$ : Mean of $\gamma_{e}$ values

$\gamma_{e, s}$ : Standard deviation of $\gamma_{e}$ values

$\delta: \quad$ Relative displacement

$\theta_{s}$ : Inclination of transverse reinforcement relative to the interfacial failure plane

$\mu$ : Coefficient of friction

$\rho_{c}$ : Unit weight of concrete

$\rho_{0}$ : Reference unit weight of concrete $\left(=2300 \mathrm{~kg} / \mathrm{m}^{3}\right)$

$\rho_{v f}$ : Transverse reinforcement ratio

$\sigma_{0}$ : Reference lateral stress normally applied to the interfacial failure plane $(=1 \mathrm{MPa})$

$\sigma_{x}$ : Lateral stress normally applied to the interfacial failure plane

$\sigma_{\text {eq }}$ : Equivalent normal compressive stress $\left(=\rho_{v f} f_{y}+\sigma_{x}\right)$

$\tau_{c}$ : Shear stress along the interfacial failure plane corresponding to relative slip $S_{c}$

$\tau_{\mathrm{cr}}:$ Initial shear cracking strength

$\tau_{n}$ : Shear friction strength

$\varphi$ : $\quad$ Friction angle of concrete along monolithic joint

$\phi^{\prime}$ : Friction angle of concrete along construction joint.

\section{Competing Interests}

The author declares that there is no conflict of interests regarding the publication of this paper.

\section{Acknowledgments}

This work was supported by Kyonggi University Research Grant 2014. 


\section{References}

[1] ACI-ASCE Committee 426, "The shear strength of reinforced concrete members," Journal of the Structural Division, vol. 99, no. 6, pp. 1091-1187, 1973.

[2] M. A. Ali and R. N. White, "Enhanced contact model for shear friction of normal and high-strength concrete," ACI Structural Journal, vol. 96, no. 3, pp. 348-360, 1999.

[3] CEB-FIP, Structural Connections for Precast Concrete Buildings, vol. 369, International Federation for Structural Concrete (fib), Lausanne, Switzerland, 2008.

[4] R. E. Loov and A. K. Patnaik, "Horizontal shear strength of composite concrete beams with a rough interface," PCI Journal, vol. 39, no. 1, pp. 48-69, 1994.

[5] A. H. Mattock, "Shear friction and high-strength concrete," ACI Structural Journal, vol. 98, no. 1, pp. 50-59, 2001.

[6] A. F. Shaikh, "Proposed revisions to shear-friction provisions," PCI Journal, vol. 23, no. 2, pp. 12-21, 1978.

[7] J. C. Walraven, J. Frenay, and A. Pruijssers, "Influence of concrete strength and load history on the shear friction capacity of concrete members," PCI Journal, vol. 32, no. 1, pp. 66-84, 1987.

[8] K. H. Yang, "Development of performance-based design guideline for high-density concrete walls," Tech. Rep., Kyonggi University, Suwon, South Korea, 2015.

[9] J. Xu, C. Wu, Z.-X. Li, and C.-T. Ng, "Numerical analysis of shear transfer across an initially uncrack reinforced concrete member," Engineering Structures, vol. 102, pp. 296-309, 2015.

[10] A. H. Mattock, "Shear transfer under monotonic loading: a cross an interface between concrete cast at different times," Tech. Rep. SM76-3, University of Washington, Seattle, Wash, USA, 1976.

[11] M. P. Nielsen and L. C. Hoang, Limit Analysis and Concrete Plasticity, Prentice-Hall, England, UK, 2011.

[12] Y. H. Hwang and K. H. Yang, "Effect of construction joint on the shear friction strength of concrete," Journal of the Architectural Institute of Korea Structure \& Construction, vol. 32, no. 6, pp. 11-18, 2016 (Korean).

[13] J. G. MacGregor and J. K. Wight, Reinforced Concrete: Mechanics and Design, Prentice Hall, Singapore, 2005.

[14] K. K. B. Dahl, "Construction joints in normal and high strength concrete," Tech. Rep. R-314, Department of Structural Engineering, Technical University of Denmark, 1994. 

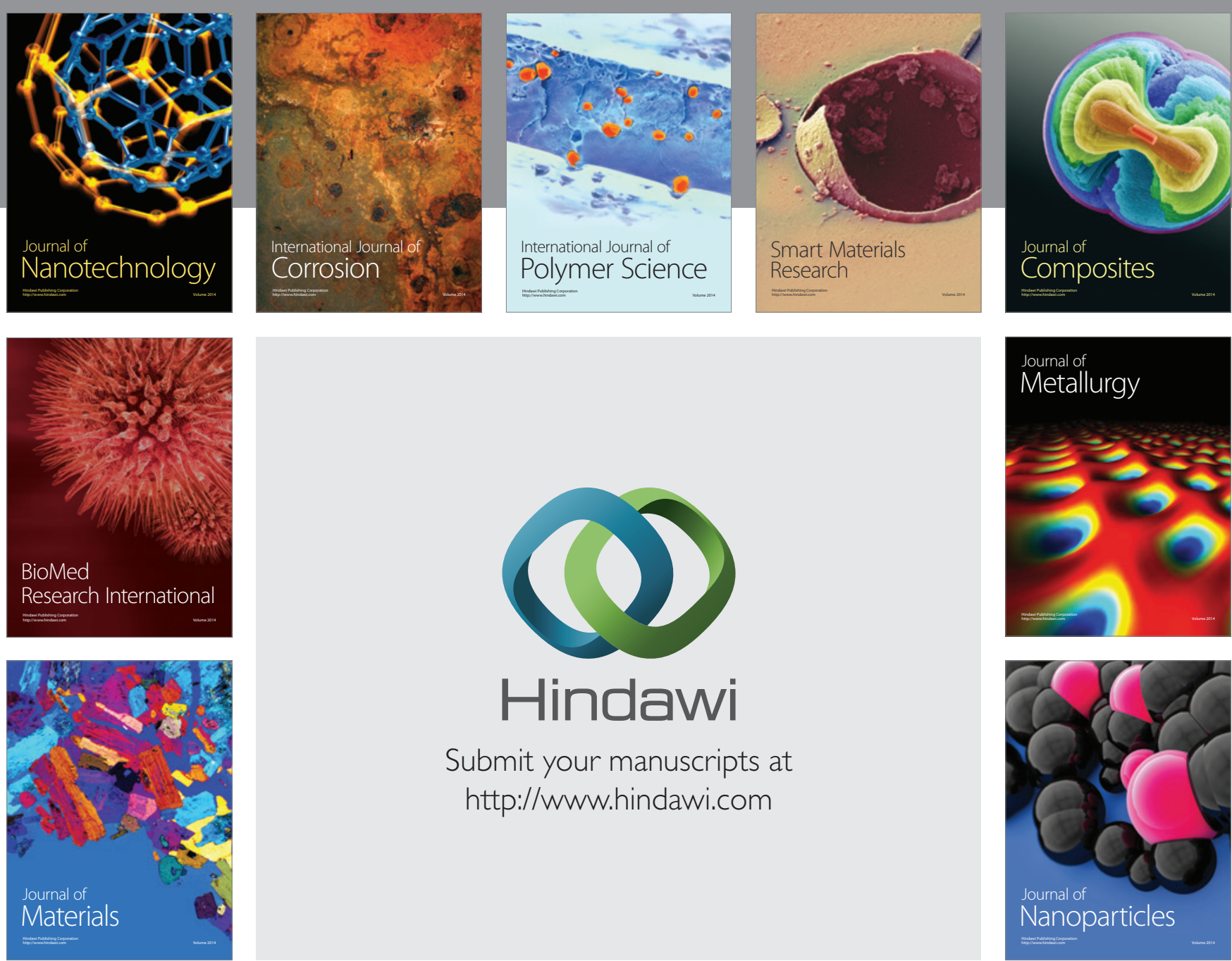

\section{Hindawi}

Submit your manuscripts at

http://www.hindawi.com

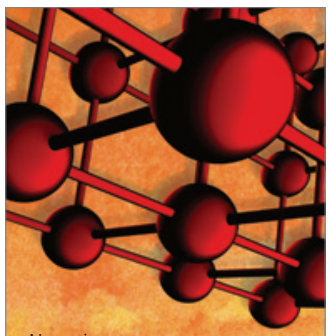

Materials Science and Engineering
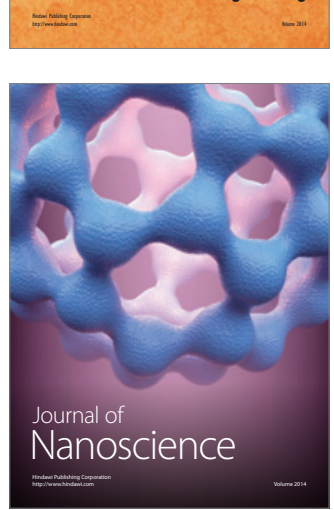
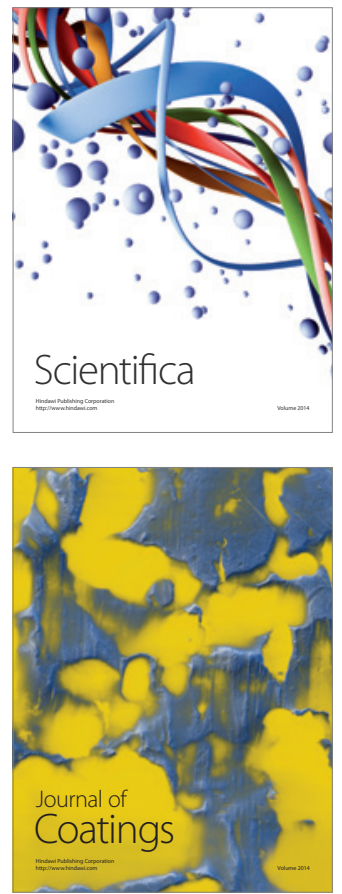
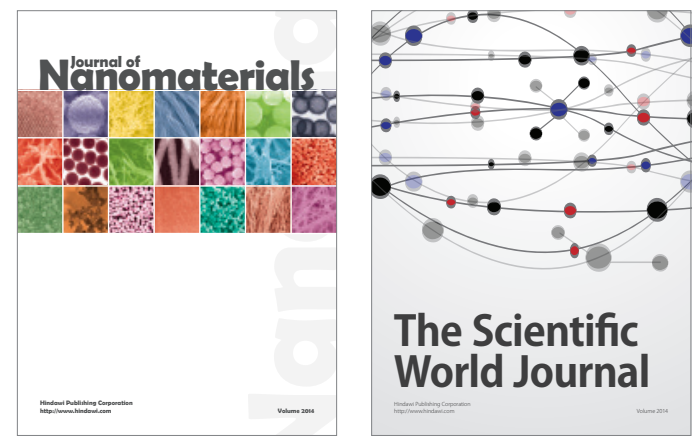

The Scientific World Journal
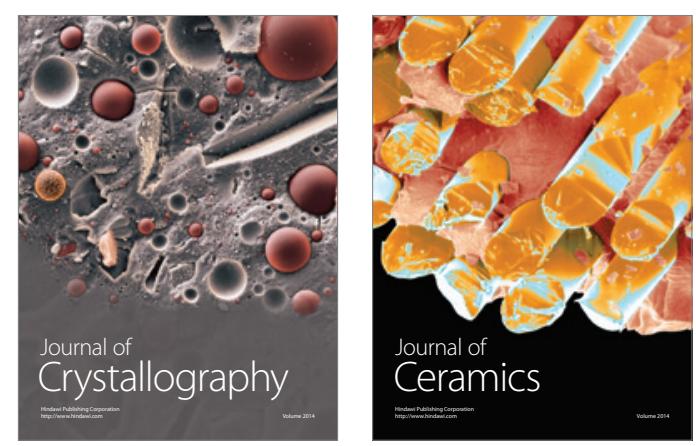
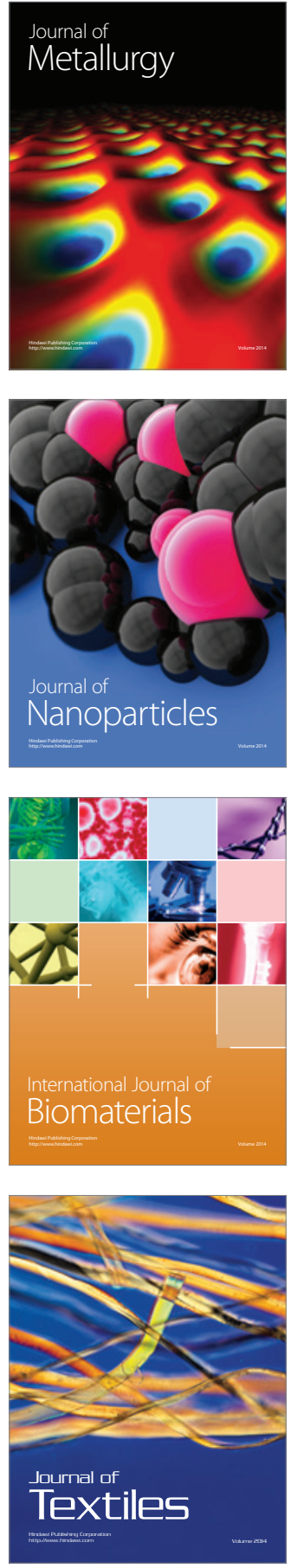